Errata

\title{
Catenulispora rubra sp. nov., an acidophilic actinomycete isolated from forest soil
}

Tomohiko Tamura, Yuumi Ishida, Takeshi Sakane and Ken-ichiro Suzuki

International Journal of Systematic and Evolutionary Microbiology (2007), 57, part 10, 2272-2274

On pages 2272 and 2273, the whole-cell sugars are given incorrectly as ribose, mannose, arabinose and glucose. The correct whole-cell sugars should be rhamnose, mannose, arabinose and galactose. In the description on page 2273, the feature of the spore chain is given incorrectly as a hook-like or flexuous manner. The correct feature of the spore chain should be a rectiflexible or straight.

\section{Mucilaginibacter paludis gen. nov., sp. nov. and Mucilaginibacter gracilis sp. nov., pectin-, xylan- and laminarin-degrading members of the family Sphingobacteriaceae from acidic Sphagnum peat bog}

Timofei A. Pankratov, Brian J. Tindall, Werner Liesack and Svetlana N. Dedysh

International Journal of Systematic and Evolutionary Microbiology (2007), 57, part 10, 2349-2354

The GenBank/EMBL/DDBJ accession number for the 16S rRNA gene sequence of Mucilaginibacter gracilis $\mathrm{TPT}_{18}^{\mathrm{T}}$ is AM490403 (not AM490402, as stated in the paper) and that for the 16S rRNA gene sequence of Mucilaginibacter paludis TPT56 ${ }^{\mathrm{T}}$ is AM490402 (not AM490403).

\section{Description of Pelomonas aquatica sp. nov. and Pelomonas puraquae sp. nov., isolated from industrial and haemodialysis water}

Margarita Gomila, Botho Bowien, Enevold Falsen, Edward R. B. Moore and Jorge Lalucat

International Journal of Systematic and Evolutionary Microbiology (2007), 57, part 11, 2629-2635

The GenBank/EMBL/DDBJ accession number for the 16S rRNA gene sequence of CCUG $52575^{\mathrm{T}}$ is AM501435 (not AM51435, as stated in the paper). 